\title{
Ultraviolet aging study on bitumen modified by a composite of clay and fumed silica nanoparticles
}

\begin{abstract}
Goshtasp Cheraghian ${ }^{\otimes}$ \& Michael P. Wistuba $(\mathbb{C}$
In this study, surface morphology, rheological and chemical properties were investigated of bitumen, which was modified by a composite of clay and fumed silica nanoparticles, and exposed to ultraviolet (UV) aging in laboratory. The volume fraction of the nanoparticles within the binder ranged from 1 to $3 \%$, the temperature range considered was 30 to $70^{\circ} \mathrm{C}$. Surface morphology, rheological and chemical binder properties were analyzed using field emission scanning electron microscopy (FESEM), dynamic shear rheometer (DSR), and Fourier transform infrared (FT-IR) spectroscopy. It was found, that the bitumen modification through clay and fumed silica nanoparticles changed resulting binder properties significantly. The index of carbonyl and oxidation degree decreased, and the clay and fumed silica nanoparticles improved aging resistance to ultraviolet (UV) radiation considerably. The results indicate that the mechanical stability of the modified bitumen is very much driven by the specific concentration of clay and fumed silica nanoparticles.
\end{abstract}

Objective of this study. Bitumen is extracted from crude oil. Its composition can be roughly grouped into maltenes (a mixture of saturates + aromatics + resins) and asphaltenes (SARA-fractions) $)^{1-3}$. It is well known that aging increases asphaltenes and resins content, while simultaneously decreasing aromatics content ${ }^{4}$, which makes the binder brittle and the asphalt pavement layer vulnerable to cracking ${ }^{5,6}$. Bituminous binders, that are most resistant to aging, are therefore of interest for asphalt pavement engineering.

Oxidation, volatilization, and steric hardening are the most important factors influencing bitumen aging. While steric hardening results from molecular rearrangement, oxidation and volatilization go together with a change of molecules. Temperature is an important factor driving these aging processes, as well as the presence of UV radiation and atmospheric oxygen in regard to oxidation aging. UV radiation may break the bonds of bitumen molecules, and may create free radicals, which in turn accelerate the aging process ${ }^{7}$. Consequently, bitumen modified by anti-aging materials that stimulate anti UV aging properties are of high interest for application in pavement engineering.

In the last decade have been many studies investigating modified bitumen with nanoparticles (NPs) ${ }^{8-10}$. Scientists and researchers are focused on new nanomaterials to meet the improve bitumen properties that conventional bitumen cannot meet these properties ${ }^{11,12}$. However, there are few works related to the effect of NPs on ultraviolet aging properties of bitumen. Titanium dioxide, cuprous oxide, zinc oxide, silicon dioxide, and montmorillonite are some NPs that have been used for improving bitumen aging resistance to UV radiation ${ }^{13-17}$.

The goal of this study was to analyze bitumen modified by a novel anti-aging additive that was composed of clay and fumed silica nanoparticles (CS-NPs; of size in the range of 10-30 nm). Due to their increased ratio of surface area to volume compared to conventional filler particles, CS-NPs enable rich binder contents in asphalt mixtures. Their large surface $\left(20-500 \mathrm{~m}^{2} / \mathrm{g}\right)$ is a unique character which promotes interaction of particles having a significant effect on the rheological and anti-aging properties of the modified binders ${ }^{18,19}$, also increasing bond strength at the aggregate-bitumen interface ${ }^{20,21}$.

Clay and fumed silica are low-cost nanomaterials, harmless and non-toxic, and they can be used as inorganic shielding ${ }^{22}$. It was reported, that clay and fumed silica nanoparticles (CS-NPs) may potentially improve bitumen mechanical and rheological properties ${ }^{23-26}$, as well as its resistance to moisture damage and aging ${ }^{27-29}$. However, the combination of both of them as a nanocomposite has not yet been used in asphalt mixture. Benefiting from 


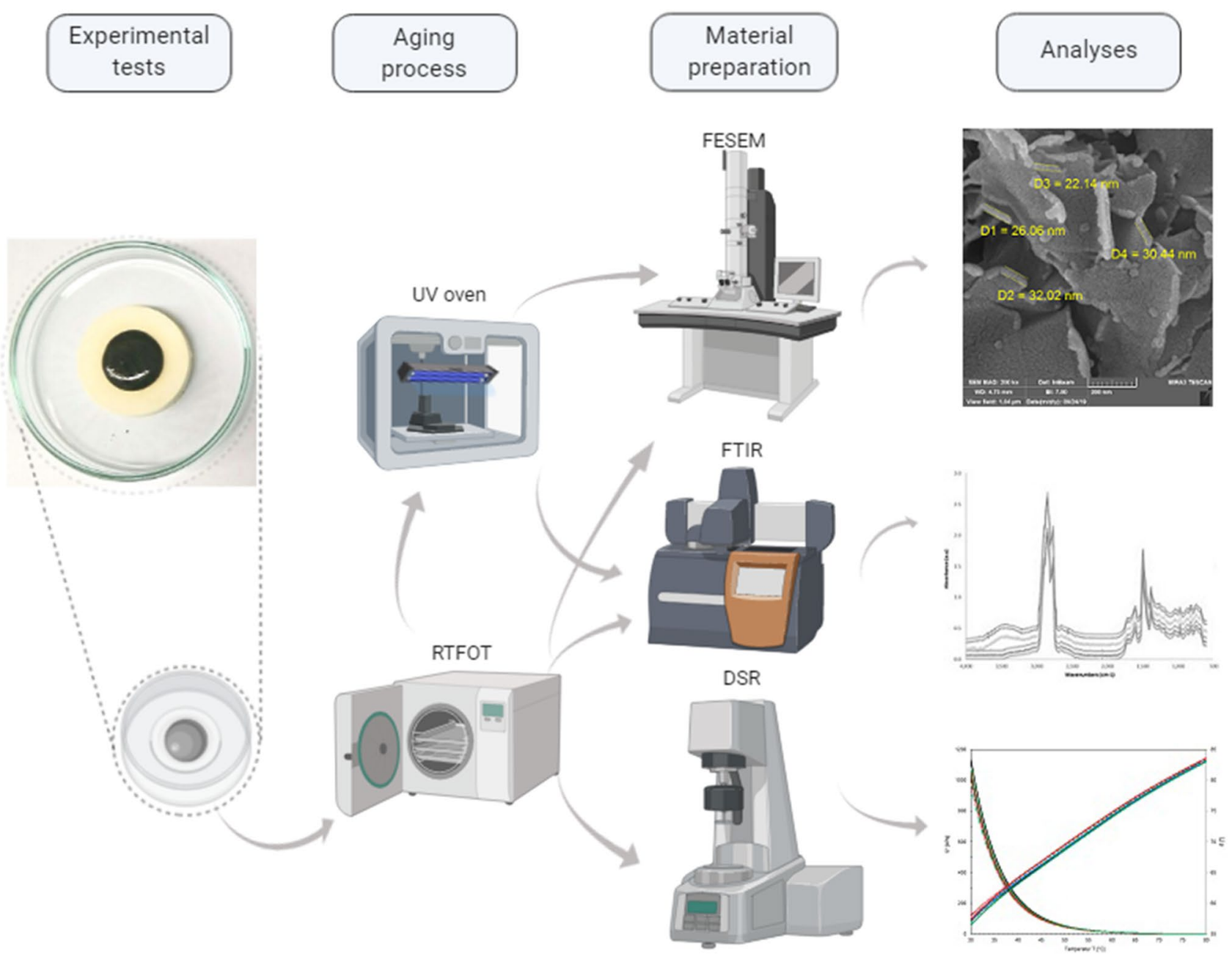

Figure 1. Schematic diagram indicating the material preparation, aging process, and experimental tests. Image partially created with BioRender.

the specific nanostructure of clay nanolayers and fumed silica nanoparticles, the stability ${ }^{30}$ and the reactivity ${ }^{31}$ of nanocomposites may be significantly improved, due to their advantageous physical properties.

This study contributes to the analysis of surface morphology, rheological and chemical binder properties of CS-NPs, in order to present new findings and to strengthen the existing knowledge on using such nanoparticles for bitumen modification.

Experimental plan. First, surface morphology of clay/fumed silica nanoparticles (CS-NPs) dispersed in the bitumen sample was studied using observations from field emission scanning electron microscopy (FESEM). Then, modified bitumen samples were prepared with different volume fractions of CS-NPs, to study the impact of CS-NPs concentration on resulting binder properties, i.e. rheological binder properties investigated through dynamic shear rheometer (DSR) measurements, and chemical binder properties from Fourier transform infrared (FT-IR) spectroscopy. Information on these test methods is reported in Fig. 1 schematically.

\section{Results and discussion}

Surface morphology identified with FESEM. Results from FESEM are shown in Fig. 2, illustrating the surface morphology of CS-NPs dispersed in the bitumen sample. A unique complex structure is formed from nanosheets. They look like petals that form structures of rosebud like shape.

Figure 2 uses colors in order to visually separate CS-NPs (colored in blue), and aggregations of CS-NPs (colored in red). The coloring is based on image analysis technique. Initial data were analyzed by a microanalysis software to measure the scale of layers and the diameter of particles. FESEM images were then processed and segmented with an image processing program, for digital analyses, and the topographical result was used as input for a professional coloring software.

When CS-NPs are blended with bitumen, the CS-NPs partially cover the bitumen surface, and when exceeding a specific threshold value the CS-NPs begin to aggregate and create a structure of multiple layers (Fig. 2a). This particle aggregation changes the homogeneity of the blend and may also change its rheological properties. In Fig. 2b, c, red color illustrates the aggregation of CS-NPs. These red sections are considered as challenging parts 

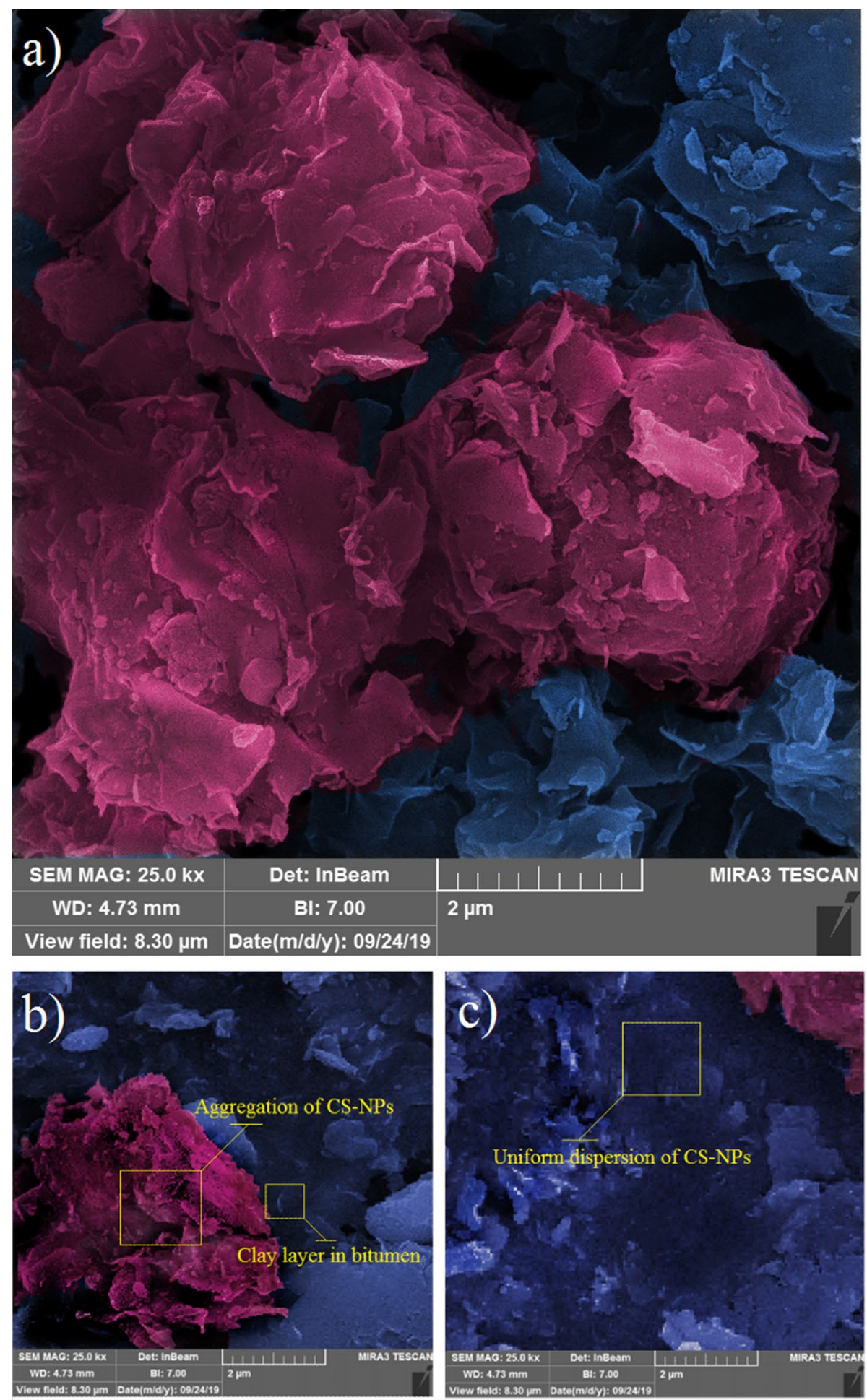

Figure 2. FESEM image of CS-NPs: (a) aggregation of clay nanoparticles form a unique chaotic structure of rosebud shape; the blue color represents uniform dispersion of CS-NPs, while aggregation of clay NPs and silica NPs are colored in red; (b) CS-NPs aggregation; and (c) uniform dispersion of CS-NPs.

of bitumen surface and are therefore further investigated in regard to the structure of clay layer with fumed silica NPs. Around the aggregation of CS-NPs, a uniform dispersion zone is seen on the bitumen surface (indicated in blue), which represents bitumen covered by a thin film of CS-NPs (single layers).

The aggregation of clay NPs were found to be uniformly dispersed in the bitumen sample, which indicates that they were uniformly dispersed during the blending process already. The sizes of aggregation of clay NPs range from 400 to $800 \mathrm{~nm}$. 


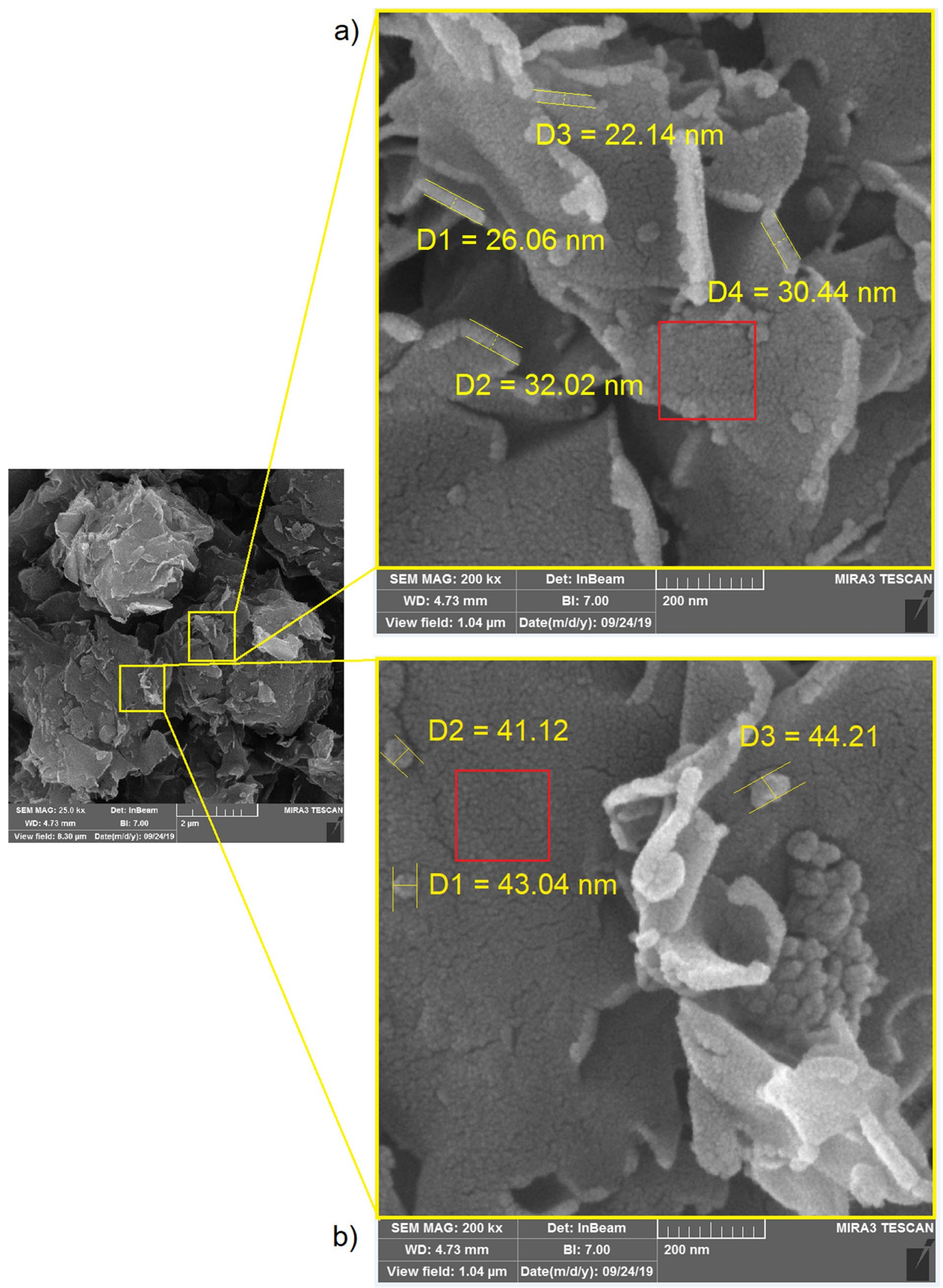

Figure 3. FESEM image of CS-NPs: (a) size of clay nanolayers; and (b) size of fumed silica nanoparticles. 
a
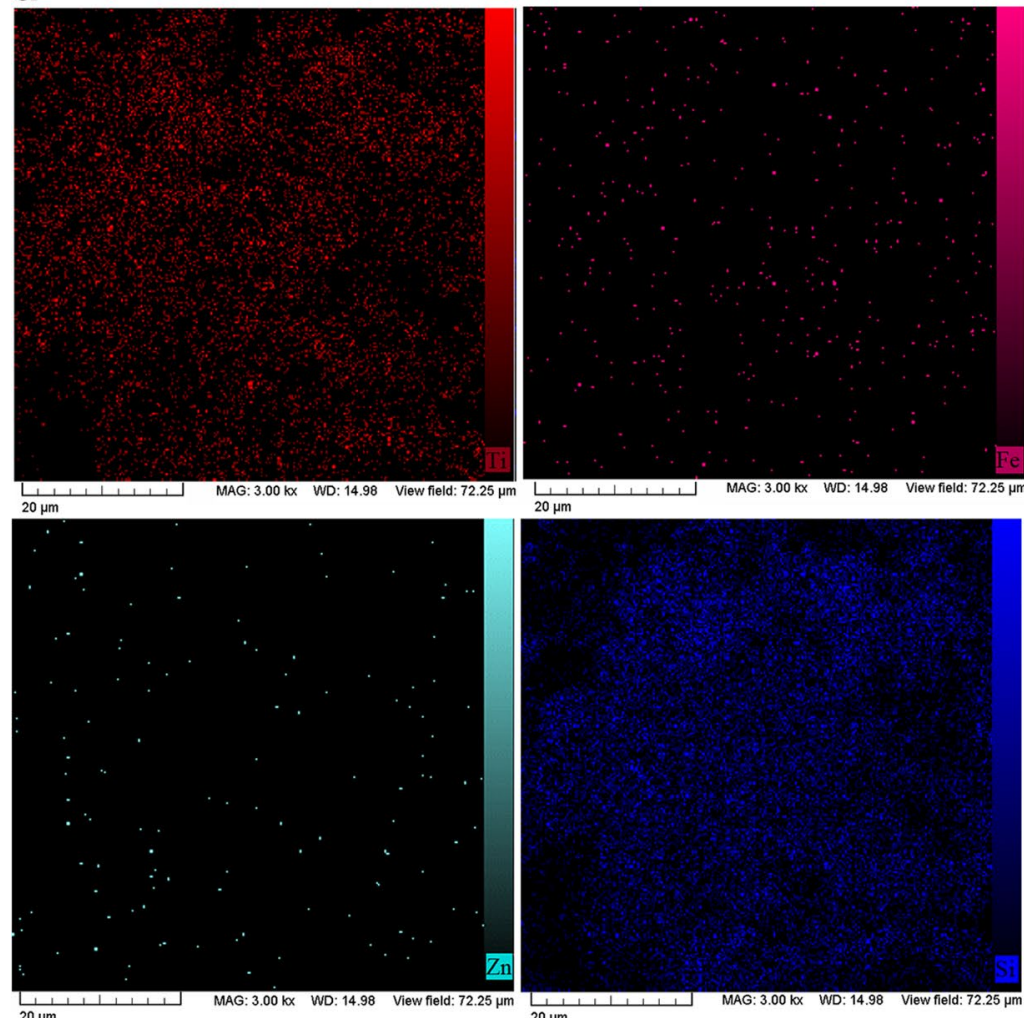

b
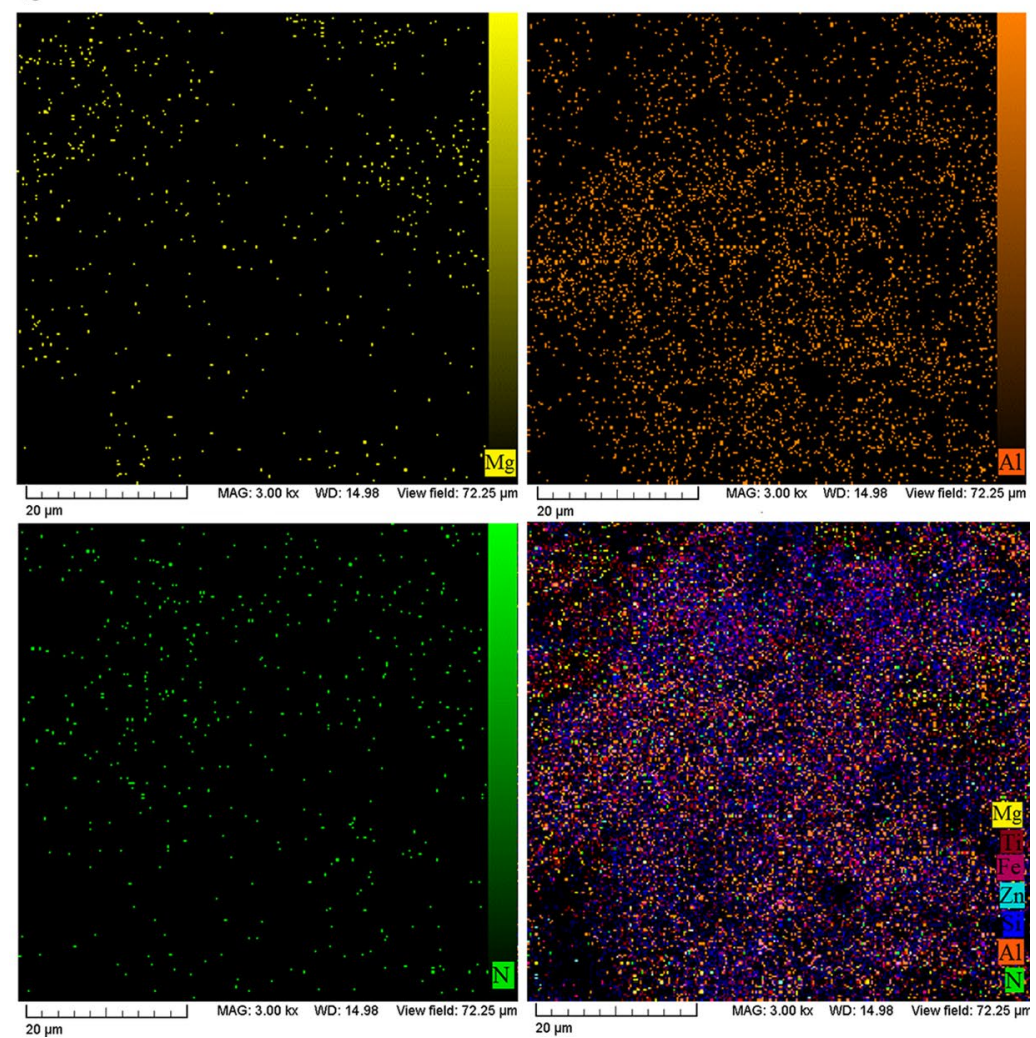

Figure 4. Analysis of bitumen modified with clay/silica nanoparticles (CS-NPs) by means of EDS mapping: elemental spot maps of titanium (Ti), iron ( $\mathrm{Fe})$, zinc $(\mathrm{Zn})$, silicon $(\mathrm{Si})$, magnesium $(\mathrm{Mg})$, aluminium $(\mathrm{Al})$, Nitrogen $(\mathrm{N})$, and combination intensity map of all seven elements. 
It is assumed, that this chaotic nanostructure in the bitumen, originating from the presence of CS-NPs, prevents the bitumen from aging: on the one hand, it acts like a radiation shield that reflects UV light and preserves the bitumen from UV light penetration. On the other hand, it traps the chemical volatile compounds of bitumen, and it prevents (or at least decelerates) their evaporation.

In Fig. 3 the red colored aggregation of clay NPs and silica NPs is illustrated more in detail, showing that some clay NPs are coated with much smaller silica NPs. Note that some silica NPs form dense bulks on the layers of clay NPs. With the increase of NPs in the surface unit, due to polarity and chemical bonding, nanolayers adsorb together and create bulkily aggregations ${ }^{32,33}$. Contrary, the blue colored structures are (advantageously) bonded with bitumen molecules and they are distributed in bitumen in terms of a uniform surface. As indicated in Fig. 3a, b, the average particle sizes of clay layers are about $27 \mathrm{~nm}$, and the silica NPs are of about $12 \mathrm{~nm}$, respectively. However, the bulk size of aggregation of silica NPs is about $42 \mathrm{~nm}$ (Fig. 3b). The red squares in Fig. 3 illustrate that clay layers may entirely be coated by fumed silica NPs.

In order to investigate the distribution of CS-NPs in bitumen, $1 \mathrm{wt} . \%$ of titanium dioxide (having $1 \mu \mathrm{m}$ average particle size) was added to a control bitumen sample modified with CS-NPs, and the distribution of elements was analyzed by Energy Dispersive X-ray (EDX) mapping. The results are illustrated in Fig. 4.

The titanium element map indicates that bitumen distribution is homogeneous. Furthermore, in order to investigate silica distribution, $0.1 \mathrm{wt}$.\% zinc oxide was added to fumed silica NPs. Based on zinc energy dispersive X-ray spectrometry (EDS) mapping ${ }^{34}$, it was found that fumed silica NPs coated clay layers uniformly. In addition, zinc dispersion indicates that this technique of producing hydrothermal CS-NPs is suitable for modified homogenous bitumen blending. The EDS map of nitrogen refers to the nitrous oxide in silica NPs, and also could be an indicator of nitrogen elements in bitumen. The dispersion of clay composing elements (silica, aluminum, and iron) on the bitumen surface was also verified by EDS mapping, where, silicon, aluminium, and iron were found to be distributed uniformly on the surface, representing a suitable saturation of CS-NPs in bitumen samples. According to the components of clay identified in previous work ${ }^{35}$, the values of iron oxide and magnesium oxide are approximately the same, which is validated in this study by the iron and magnesium elements maps. Furthermore, the combination map confirms the successful coating of fumed silica NPs on clay nanolayers.

Rheological properties identified with DSR. Complex modulus and phase angle. Rheological properties of bitumen modified by CS-NPs were studied in dynamic shear rheometer (DSR) based on measurements of complex shear modulus $\mathrm{G}^{*}$ and corresponding phase angle $\delta$, both depending on temperature and loading frequency ${ }^{36,37}$.

The bitumen samples were investigated before and after laboratory aging. Laboratory aging was conducted through Rolling Thin Film Oven Test (RTFOT), referred to as short term aging procedure according to the US Standard (ASTM D1754), and through exposure to UV radiation for durations of 6 days and of 12 days.

The results representing a temperature range from 30 to $80^{\circ} \mathrm{C}$ are shown in Fig. 5.

The level of complex shear modulus was found to be significantly higher for bitumen samples modified with CS-NPs than for unmodified control bitumen samples. Hence, the addition of $0.2 \mathrm{wt}$.\% of CS-NPs increases stiffness (and thus deformation resistance of the corresponding asphalt mixture). Ranking of samples before aging was

- for complex shear modulus $\mathrm{G}^{*}$ :

without CS-NPs < with 0.1 wt.\% of CS-NPs < with 0.3 wt.\% of CS-NPs < with 0.2 wt.\% of CS-NPs,

- and for phase angle $\delta$ : with 0.2 wt.\% of CS-NPs > without CS-NPs > with 0.1 wt.\% of CS-NPs > with 0.3 wt.\% of CS-NPs.

Because of laboratory aging, stiffness levels are increased, and phase angles are decreased. This goes together with a distinct increase in the bitumens' elastic behavior ${ }^{23}$. According to Fig. 5, the bitumen sample including 0.2 wt.\% CS-NPs shows highest stiffness in short-term aging.

In Fig. 6, the results UV aging are illustrated, indicating that UV aging increases complex shear modulus of the unmodified control bitumen. Remarkably, for bitumen modified with CS-NPs the aging effect is reversed. The ranking of complex shear modulus and of phase angle in 6 days of UV aging was found to be.

- for complex shear modulus $\mathrm{G}^{\star}$ :

with 1.0 wt. $\%$ of CS-NPs > without CS-NPs > with 3.0 wt. $\%$ of CS-NPs > with 2.0 wt.\% of CS-NPs,

- and for phase angle $\delta$ :

with 3.0 wt.\% of CS-NPs < with 1.0 wt.\% of CS-NPs < with 1.0 wt. $\%$ of CS-NPs $<$ without CS-NPs.

Maximum and minimum values of complex shear modulus and phase angle in 12 days of UV aging are observed for the sample with $0.2 \mathrm{wt}$ \% CS-NPs, and the sample with $0.1 \mathrm{wt} . \%$ CS-NPs. The sample with 0.2 wt.\% of CS-NPs is assumed to be most UV resistant, as an optimum percent of CS-NPs can be considered most efficient to shield the bitumen from UV radiation.

Resistance to permanent deformation. Figure 7 displays permanent deformation resistance of bitumen samples between temperatures of $30^{\circ} \mathrm{C}$ and $70^{\circ} \mathrm{C}$, before and after laboratory aging. The rutting factor indicates rutting resistance or stiffness of bitumen at high temperature. Based on the US-Standard AASHTO T 315, complex modulus and phase angle at $10 \mathrm{rad} / \mathrm{s}$ were selected for calculating the rutting factor ${ }^{37}$. 

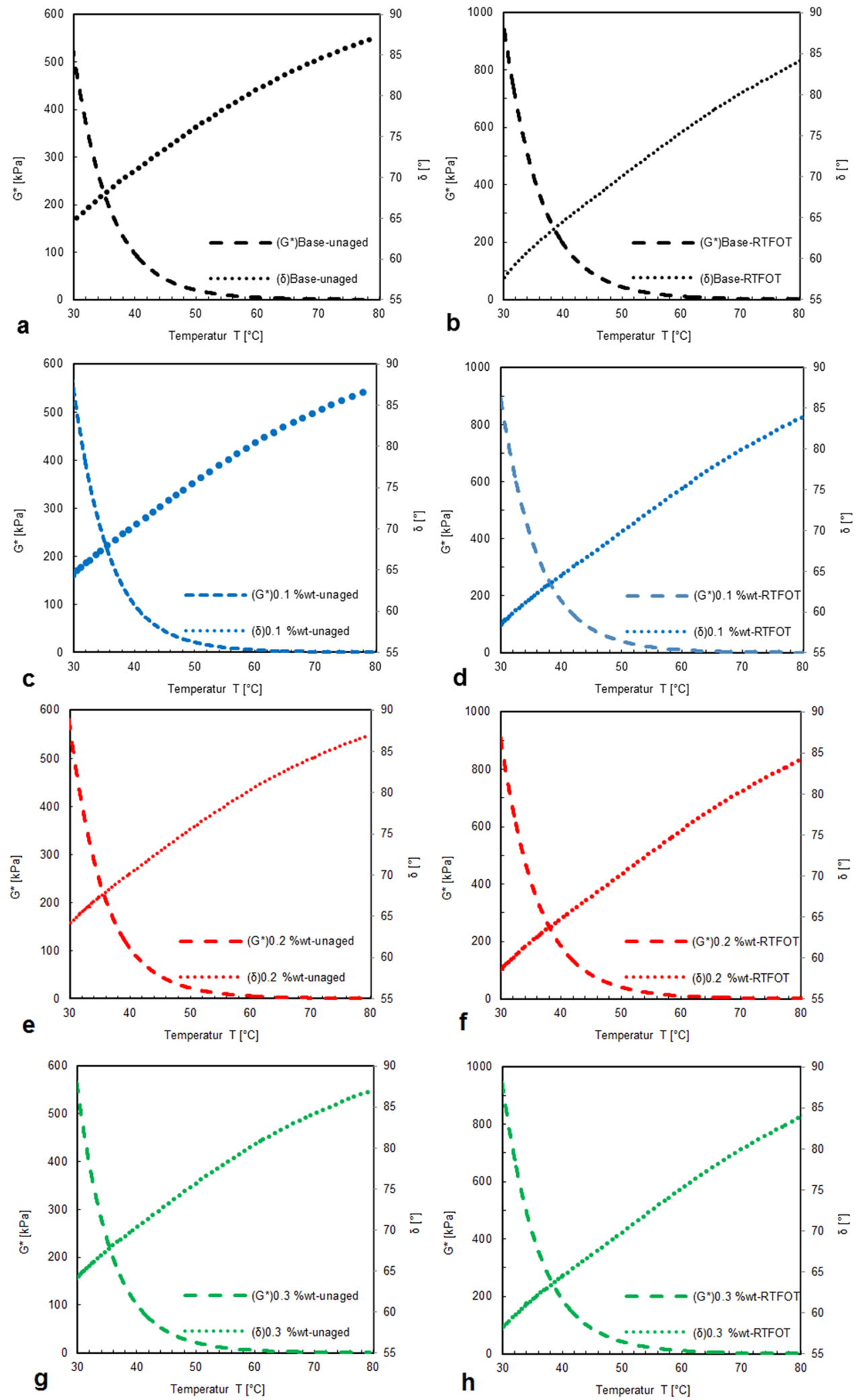

Figure 5. Complex modulus and phase angle of modified bitumen with CS-NPs before laboratory aging $(\mathbf{a}, \mathbf{c}, \mathbf{e}, \mathbf{g})$ and after $(\mathbf{b}, \mathbf{d}, \mathbf{f}, \mathbf{h})$ short-term aging in the Rolling Thin Film Oven Test (RTFOT), with different concentrations: without CS-NPs $(\mathbf{a}, \mathbf{b})$, with 0.1 wt.\% CS-NPs $(\mathbf{c}, \mathbf{d})$, with $0.2 \mathrm{wt} . \%$ CS-NPs $(\mathbf{e}, \mathbf{f})$, and with 0.3 wt.\% CS-NPs $(\mathbf{e}, \mathbf{g})$. 

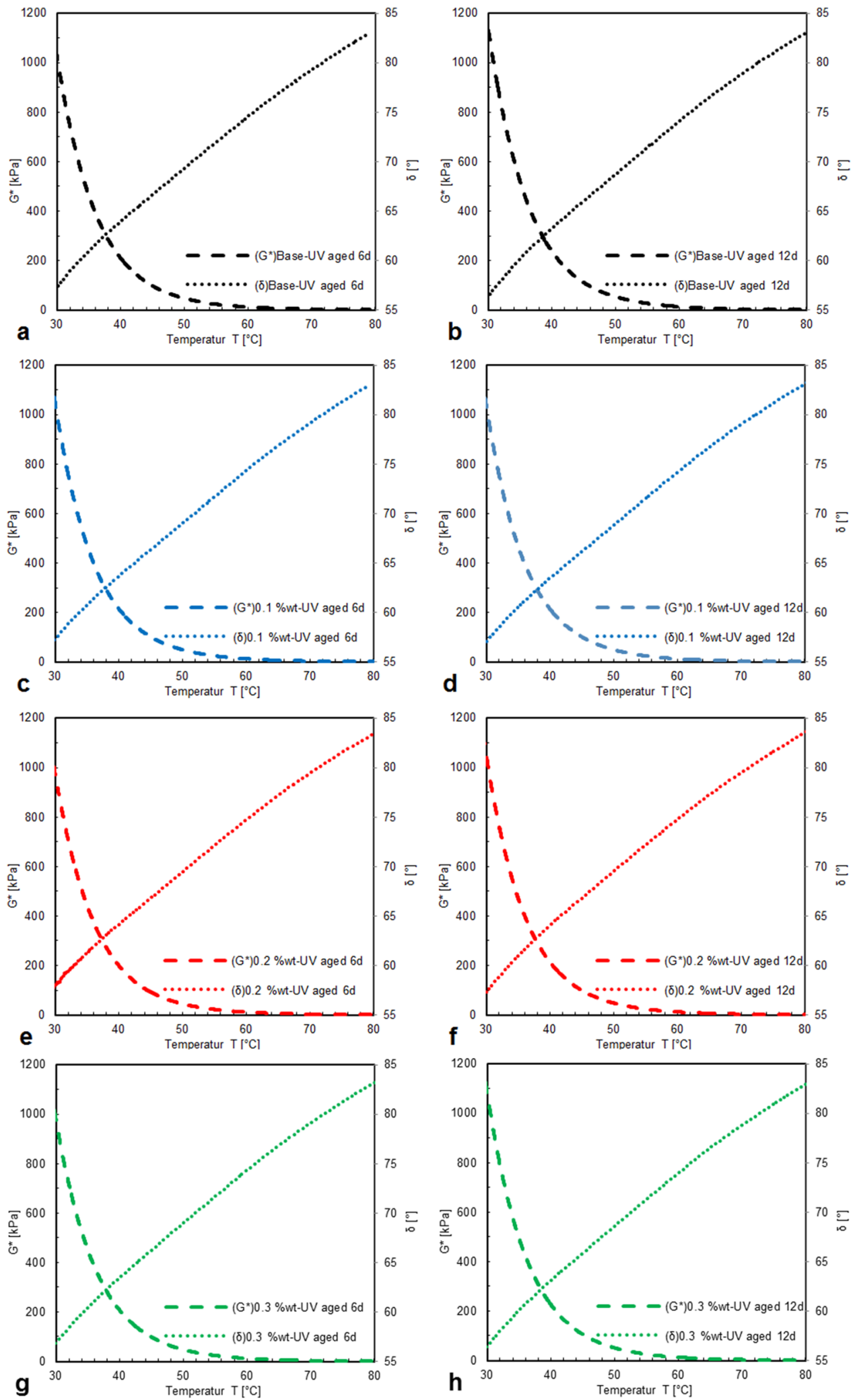

Figure 6. Complex shear modulus $\mathrm{G}^{*}$ and phase angle $\delta$ of bitumen modified with CS-NPs after UV aging of 6 days $(\mathbf{a}, \mathbf{c}, \mathbf{e}, \mathbf{g})$ and 12 days $(\mathbf{b}, \mathbf{d}, \mathbf{f}, \mathbf{h})$; bitumen samples of different concentrations: without CS-NPs $(\mathbf{a}, \mathbf{b})$, with 0.1 wt. $\%$ of CS-NPs $(\mathbf{c}, \mathbf{d})$, with 0.2 wt.\% of CS-NPs $(\mathbf{e}, \mathbf{f})$, and with 0.3 wt. $\%$ of CS-NPs $(\mathbf{e}, \mathbf{g})$. 

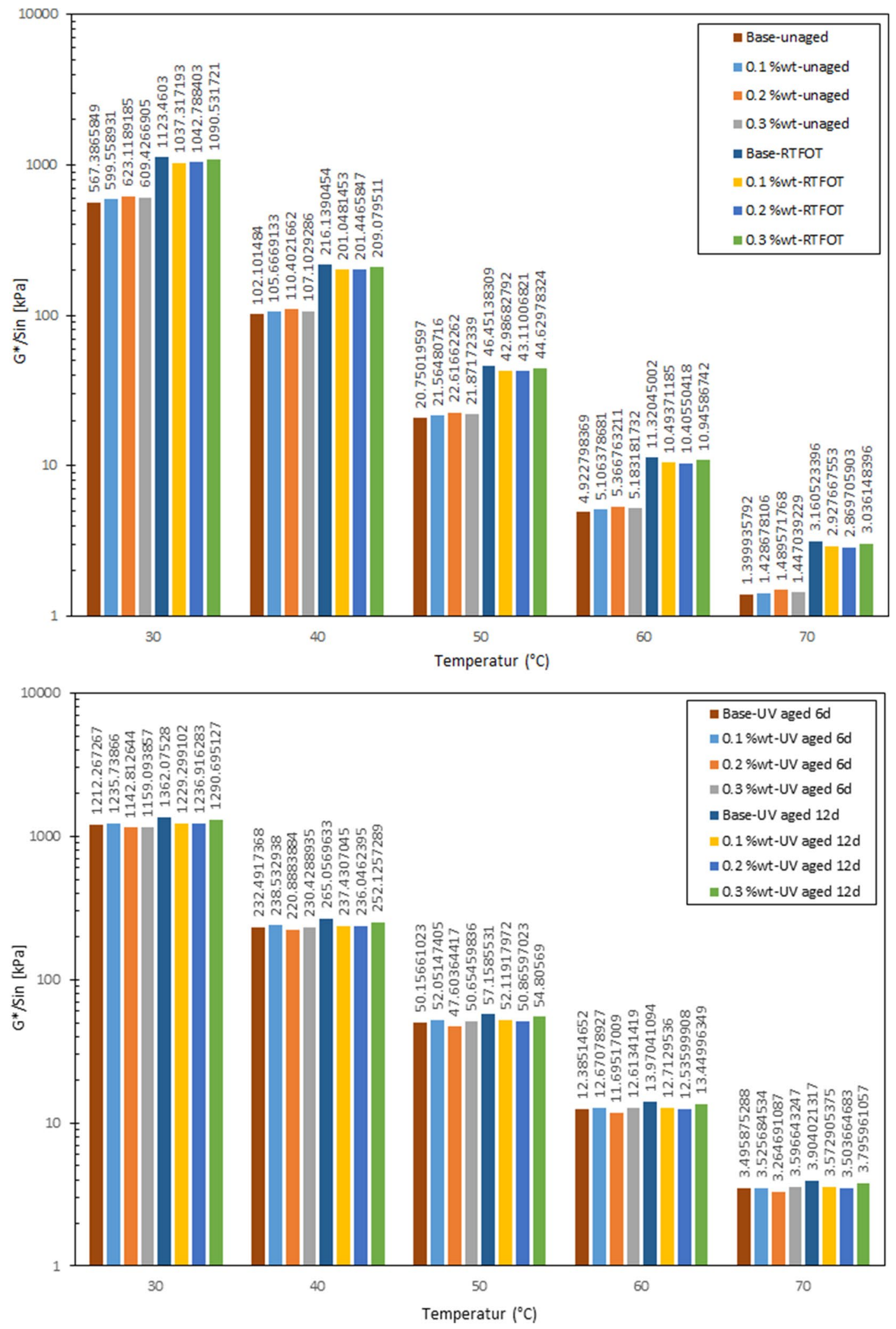

Figure 7. Rutting resistance of bitumen modified with CS-NPs in unaged condition, in short-term aged condition (RTFOT), and in UV aged condition. 


\begin{tabular}{|c|c|c|c|c|c|c|c|c|c|c|c|c|c|c|c|}
\hline \multicolumn{16}{|c|}{ Threshold temperatures $\left({ }^{\circ} \mathrm{C}\right)$} \\
\hline \multicolumn{4}{|c|}{$\begin{array}{l}\text { Before aging }\left(G^{*} / \sin \right. \\
\delta=1 \mathrm{kPa})\end{array}$} & \multicolumn{12}{|c|}{ After aging $\left(G^{*} / \sin \delta=2.2 \mathrm{kPa}\right)$} \\
\hline S1 & S2 & S3 & S4 & S5 & S6 & S7 & S8s & S9 & $\mathrm{S} 10$ & S11 & S12 & S13 & S14 & S15 & S16 \\
\hline 72.8 & 73.1 & 73.4 & 73.1 & 73.0 & 72.4 & 72.9 & 72.7 & 73.9 & 73.9 & 73.3 & 74.2 & 74.8 & 74.1 & 73.9 & 74.6 \\
\hline
\end{tabular}

Table 1. Bitumen threshold temperatures in different concentrations of CS-NPs before and after aging.

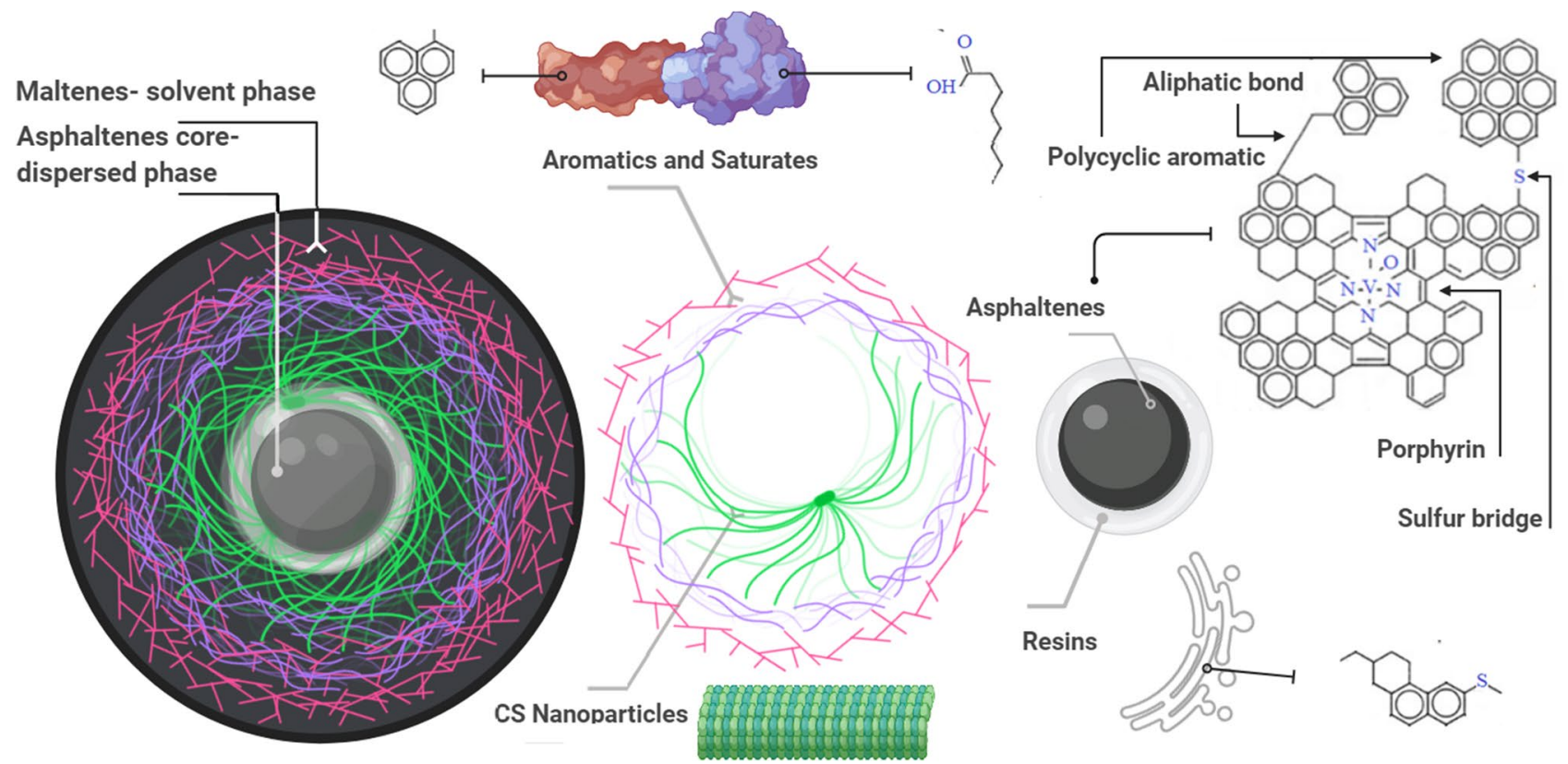

Figure 8. Schematic illustration of the CS-NPs action in the colloidal structure of bitumen.

After short-term aging (through RTFOT), the rutting factor increases for the unmodified control bitumen, while for the bitumen samples modified with CS-NPs the rutting factor decreases. Hence, a better resistance to permanent deformation can be assumed for the bitumen samples modified with CS-NPs.

The results also show that the influence of short-term aging on the resistance to permanent deformation is more dominant than the influence of UV aging. Nevertheless, the effect of UV aging is undeniable. During UV aging, the bitumen sample modified with $0.3 \mathrm{wt} . \%$ of CS-NPs is less changed, than the control bitumen sample, while other concentrations of NPs have remarkable effects on the resistance to permanent deformation. As highlighted in Fig. 7, the value of the bitumen sample modified with $0.2 \mathrm{wt}$.\% of CS-NPs is the smallest, which indicates that CS-NPs cause a high resistance to UV radiation.

In this study, rutting resistance is judged based on the threshold temperatures derived from the performance grade approach as proposed by SHRP Standard (SHRP-A-369) ${ }^{38-40}$. Based on the results represented in Table 1, the temperatures at which $\mathrm{G}^{*} / \sin \delta$ equals $1 \mathrm{kPa}$, and $2.2 \mathrm{kPa}$ respectively, are used as threshold temperatures before and after aging (according to SHRP standard). These results indicate that the CS-NPs decreased the rutting resistance of the bitumen sample before aging. During aging, the threshold temperatures of the control bitumen samples were increased, and thus, the bitumen samples became harder. Addition of CS-NPs decreased the threshold temperature.

From these results it can be concluded that the bitumen modification with CS-NPs reduces the stiffness increase of bitumen samples subjected to UV aging and retards bitumen hardening in consequence of aging. Moreover, the results show that the addition of 0.1 and $0.2 \mathrm{wt} . \%$ of CS-NPs results in preferable performance after short-term aging and UV aging than higher concentrations.

Interaction of bitumen and nanoparticles. In order to investigate potential reasons for the anti-aging effects of bitumen with nanoparticles, the molecules' interactions need to be considered. Initial interaction is related to increasing hydroxy groups bondings between bitumen and silica NPs surfaces. This subject is due to the high surface energy of silica nanoparticles ${ }^{41,42}$. In addition, the high surface area to volume ratio of clay nanolayers is a significant factor which increases the ability of bitumen molecules to interact with clay layers ${ }^{11}$. In other words, silica NPs are connected with bitumen molecules by chemical bonds, and bitumen components interact with NPs by means of physical reactions (van der Waals forces) ${ }^{43}$.

Based on the colloidal structure of bitumen (Fig. 8), asphaltenes are the dispersed phase in the solvent phase. The average diameter of asphaltenes is $0.5-40 \mathrm{~nm}^{44,45}$, and therefore they can create significant changes in material 


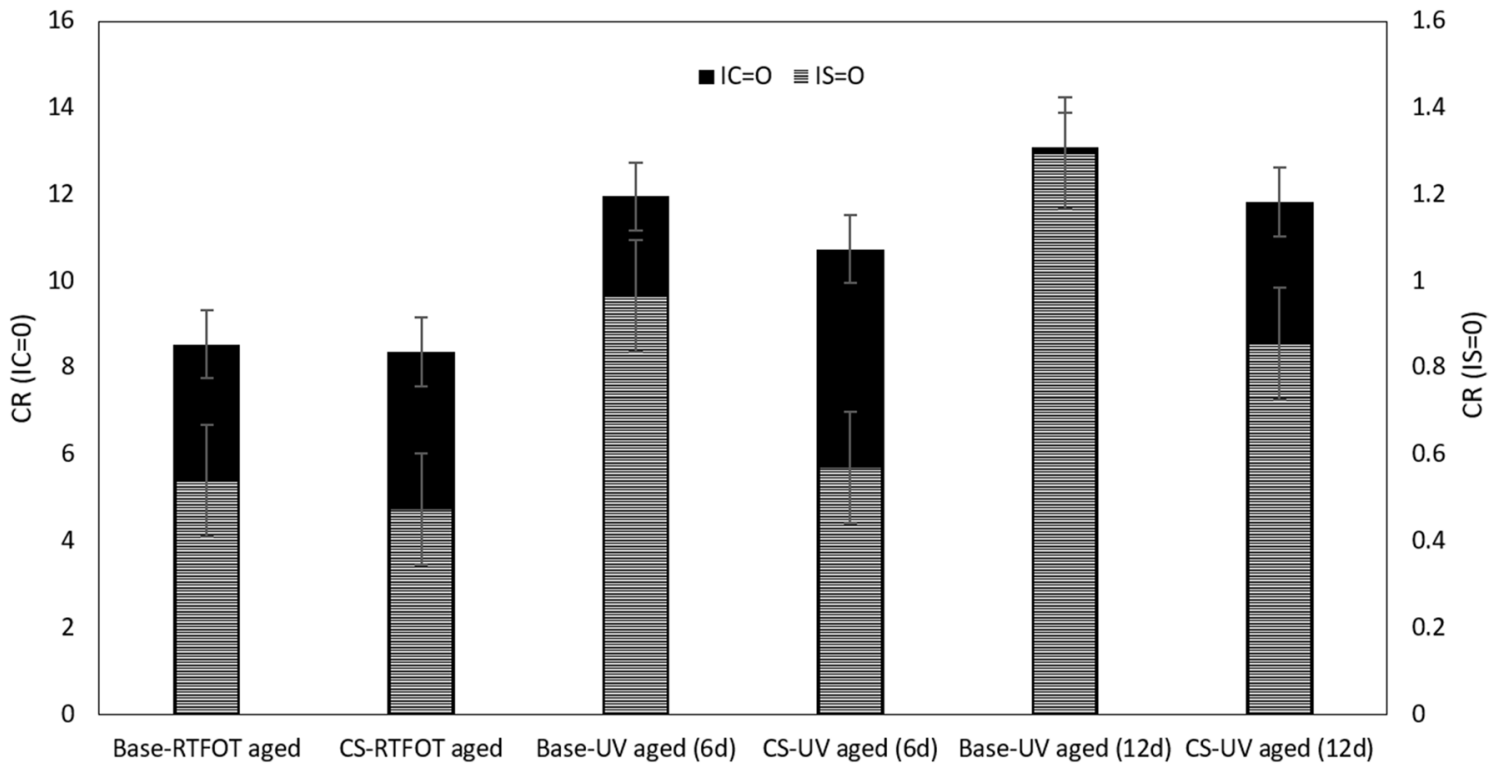

Figure 9. Aging indexes based on carbonyl and sulfoxide groups for different aging conditions.

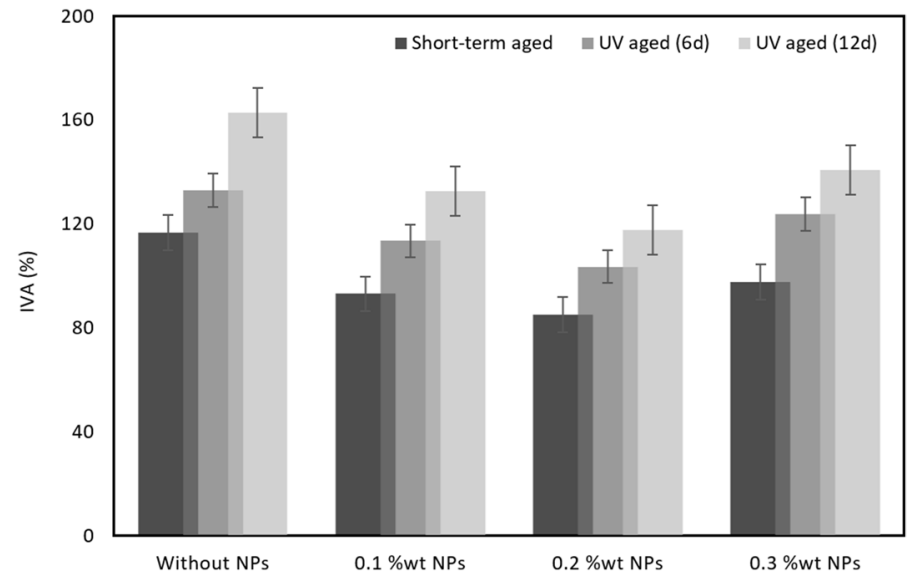

Figure 10. Index of viscosity aging (IVA) of control bitumen and of bitumen modified with CS-NPs.

nature. CS-NPs (average particle sizes of clay NPs and silica NPs are about 12 and $33 \mathrm{~nm}$, respectively) may chemically react and disperse between these colloidal dimensions (schematically shown in Fig. 8).

Furthermore, nanolayers of clay change the surface characteristics of bitumen. The polarity of clay layers (related to some elements) decreases the polarity and adsorption of asphaltenes. This is a complex mechanism in which sodium elements (which exist in clay) adsorbed by asphaltene carbons cause saturate molecules.

They disperse in the colloidal structure of bitumen with nanolayers of $1-100 \mathrm{~nm}$ in scale, which hinders the penetration of oxygen to the bitumen ${ }^{46}$. The nanoparticles also increase the stability of modified bitumen and avoid destruction of the chemical structure of bitumen components. However, excessive use of clay NPs may destroy the elastic properties of bitumen ${ }^{47}$. Note that there are most probably other chemical and physical properties of these nanoparticles in addition, such as ion exchange reactions and wettability alteration ${ }^{48}$.

Chemical composition identified with FT-IR. Figure 9 presents the change rate (CR) of the carbonyl and sulfoxide index for short term and for UV aging. The carbonyl index increased more for UV aged samples than for control bitumen samples. The carbonyl and sulfoxide index is decreased for bitumen samples modified with CS-NPs. Furthermore, carbonyl and sulfoxide index increased with expanding aging time.

Figure 9 shows the difference in CR when carbonyl is increased to 3.41, and to 1.08 respectively, and in sulfoxide index when sulfoxide is increased to 0.426 , and to 0.285 respectively, 6 and 12 days of UV radiation, without and with NPs. These data indicate that the use of CS-NPs results in suitable performance due to their efficient UV-shielding coating. It can be assumed, that NPs with nano-diameter have an excellent capability to absorb UV light ${ }^{49}$, and in addition, clay nano layer is a suitable material in reflecting UV light. The results indicate that 


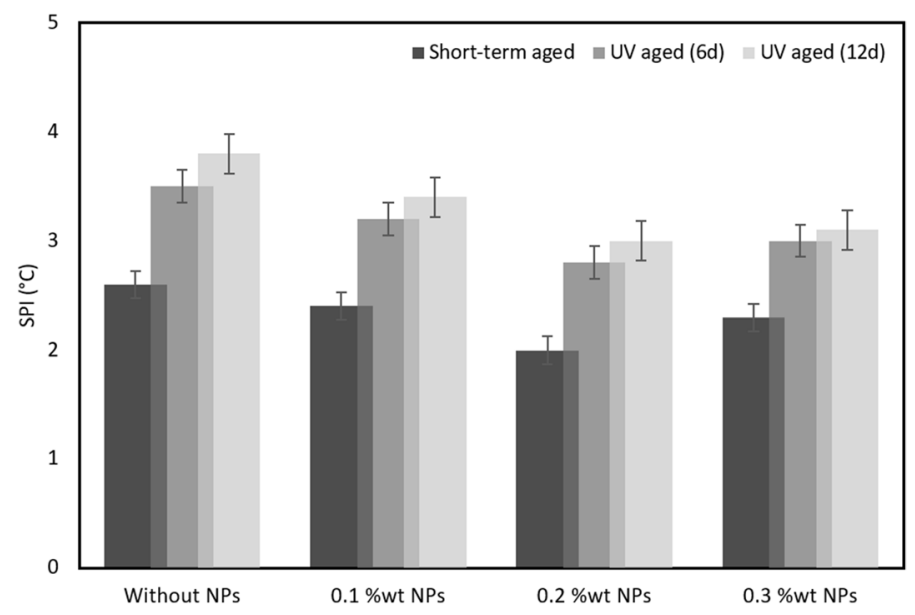

Figure 11. Softening point increment (SPI) of control bitumen and of aged bitumen modified with CS-NPs.

increasing the content of NPs by more than 0.2 wt.\% will increase UV aging resistance significantly. However, the optimum content depends on many factors, such as type, size and solvent of NPs in mortar and in bitumen ${ }^{50}$.

Mechanical properties. For validation of FTIR results, the index of viscosity aging (IVA) and softening point increment (SPI) are used ${ }^{31}$. IVA and SPI are computed from Eqs. (1) and (2):

$$
\text { IVA }=\frac{\text { viscosity of bitumen after aging }- \text { viscosity of unaged bitumen }}{\text { viscosity of unaged bitumen }}
$$

$$
\text { SPI }=\text { softening point of aged bitumen }- \text { softening point of unaged bitumen }
$$

After short term aging and UV aging, IVA decreases for samples modified by CS-NPs, which confirms the findings stated earlier (Fig. 10). IVA is increased, when the duration of UV aging is increased. This can be seen in Fig. 10, where smallest level of IVAs are found for samples S11 and S15, 6 and 12 days of UV aging. Moreover, an increase of the concentration of fumed silica nanoparticles in bitumen goes together with an increase in IVA and a reduction in aging resistance. SPI values for bitumen samples with different contents of CS-NPs are shown in Fig. 11. These results illustrate that the effect of CS-NPs is more distinct for UV aging than for short term aging.

\section{Conclusions}

Surface morphology, rheological and chemical properties were investigated of bitumen, which was modified by a composite of clay and fumed silica nanoparticles, and exposed to ultraviolet (UV) aging in laboratory. The volume fraction of the nanoparticles within the binder ranged from 1 to $3 \%$, the temperature range considered was 30 to $70^{\circ} \mathrm{C}$. Surface morphology, rheological and chemical binder properties were analyzed using field emission scanning electron microscopy (FESEM), dynamic shear rheometer (DSR), and Fourier transform infrared (FT-IR) spectroscopy. From these investigations, the following main conclusions can be drawn:

The bitumen modification through clay and fumed silica nanoparticles changed binder properties significantly. The distinct surface of clay nanolayers and the high UV reflectivity of fumed silica NPs caused a change in bitumen performance. The index of carbonyl and oxidation degree decreased, and the clay and fumed silica nanoparticles improved aging resistance to ultraviolet (UV) radiation considerably, as shown by FTIR results. It is concluded that clay and fumed silica nanoparticles may potentially be used as efficient UV-shielding coatings in asphalt pavements.

Adding clay and fumed silica nanoparticles to bitumen reduced stiffness distinctly, and improved resistance to permanent deformation. The results indicate that the mechanical stability of the modified bitumen is very much driven by the specific concentration of clay and fumed silica nanoparticles. The DSR and FT-IR results indicate that increasing the content of NPs by more than $0.2 \mathrm{wt}$.\% will increase UV aging resistance significantly. Moreover, deformation resistance shows the bitumen modification with CS-NPs reduces the stiffness increase of bitumen samples subjected to UV aging and retards bitumen hardening in consequence of aging.

Bitumen modification through clay and fumed silica nanoparticles can be considered as an interesting lowcost technique in asphalt pavement engineering providing novel perspectives in making asphalt materials more durable. From a broader perspective, our findings of molecular interactions between nanoparticles and bitumen will open up a new avenue that will be an inspiration in the nanotechnology concept in asphalt. 


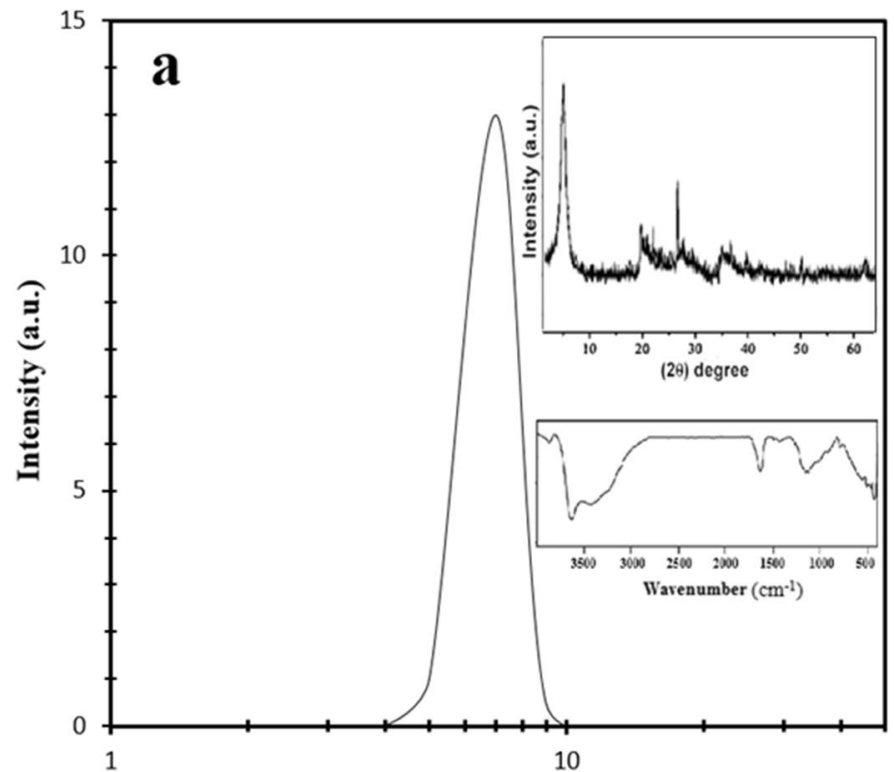

Diameter size (nm)

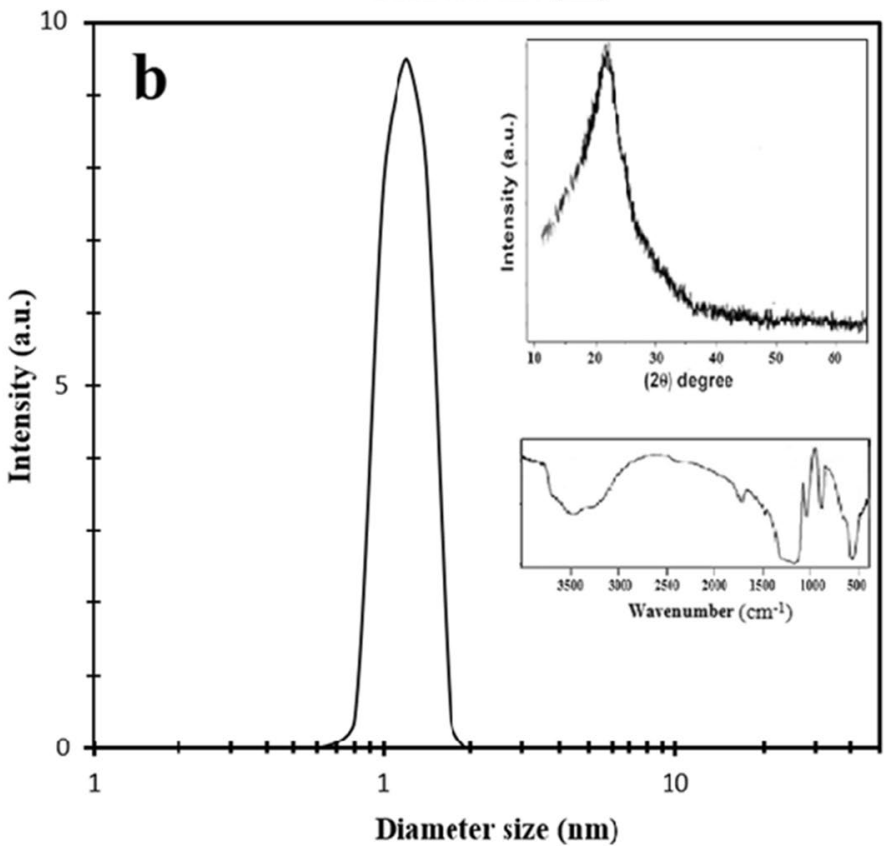

Figure 12. DLS distribution, XRD pattern, and Fourier transform infrared spectra of (a) clay; and (b) fumed silica.

\section{Methods}

Materials and synthesis. In the present research, sodium bentonite (Sigma Aldrich Ltd., Germany), nano fumed silica (Aerosil A300, Degussa Co., Germany), and 50/70 penetration grade bitumen (Total Co., France) were used. The montmorillonite chemical composition is reported as follows: $61.03 \% \mathrm{SiO}_{2}, 14.59 \% \mathrm{Al}_{2} \mathrm{O}_{3}, 2.22 \%$ $\mathrm{MgO}, 0.22 \% \mathrm{TiO}_{2}, 2.09 \% \mathrm{Fe}_{2} \mathrm{O}_{3}, 2.04 \% \mathrm{Na}_{2} \mathrm{O}, 0.76 \% \mathrm{~K}_{2} \mathrm{O}$ and $0.77 \% \mathrm{CaO}$.

Clay/silica was prepared with hydrothermal syntheses method using a procedure adapted from Yang et al. ${ }^{51}$ and Cheraghian et al. ${ }^{30,52}$. The size distribution of materials and X-ray diffraction (XRD) pattern were evaluated with dynamic light scattering (DLS) (Malvern ZEN 3600, UK) and X-ray powder diffraction (Philips PW 1730, Netherlands) analyses, as shown in Fig. 12. After purification of montmorillonite, it was milled to exchange $98 \mathrm{mmol} / 100 \mathrm{~g}$ cation capability. Then, $4 \mathrm{~g}$ of montmorillonite and $0.48 \mathrm{~g}$ of $\mathrm{NaOH}$ were dissolved for $3 \mathrm{~h}$ within $200 \mathrm{ml}$ deionized water at a temperature of $25^{\circ} \mathrm{C}$, and thereupon, they were dispersed by ultrasonic mixer. Then, $2 \mathrm{ml}$ of polyethyleneglycol (PEG) and $4 \mathrm{~g}$ of cetyltrimethylammoniumbromid (CTAB) were dispersed in $40 \mathrm{ml}$ of distilled water. PEG/CTAB solution was blended to the mixture for $3 \mathrm{~h}$, and at the same time $10 \mathrm{ml}$ of tetraethylorthosilicate (TEOS) was injected to the suspension. The mixed materials in a stainless-steel autoclave were heated to a temperature of $180^{\circ} \mathrm{C}$ for $16 \mathrm{~h}$, and then that the materials were cooled down to $25^{\circ} \mathrm{C}$. Finally, 

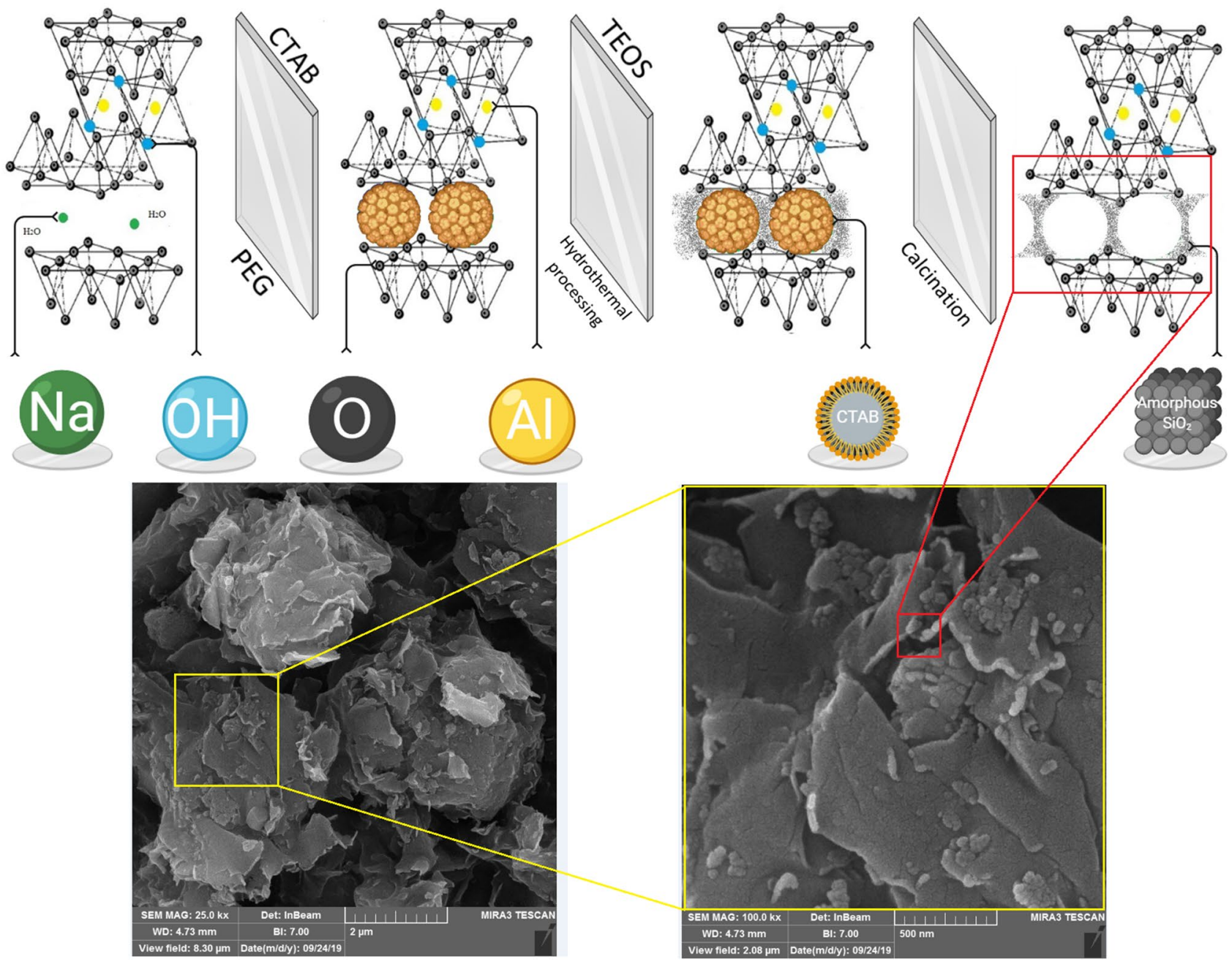

Figure 13. Schematic illustration of multistep synthesis of CS-NPs.

\begin{tabular}{|l|l|l|l|l|l|}
\hline Sample no. & Content of CS-NPs (wt.\%) & Ageing process & Sample no. & Content of CS-NPs (wt.\%) & Aging process \\
\hline S1 & - & Unaged & S9 & - & 6d UV \\
\hline S2 & 0.1 & Unaged & S10 & 0.1 & 6d UV \\
\hline S3 & 0.2 & Unaged & S11 & 0.2 & 6d UV \\
\hline S4 & 0.3 & Unaged & S12 & 0.3 & 6d UV \\
\hline S5 & - & RTFO & S13 & - & 12d UV \\
\hline S6 & 0.1 & RTFO & S14 & 0.1 & 12d UV \\
\hline S7 & 0.2 & RTFO & S15 & 0.2 & 12d UV \\
\hline S8 & 0.3 & RTFO & S16 & 0.3 & 12d UV \\
\hline
\end{tabular}

Table 2. Overview of sample aging processes.

the powders were heated to eliminate the organic surfactant. Figure 13 indicates the schematic synthesis process of clay and fumed silica.

Ageing process. For Rolling Thin Film Oven Test (RTFOT), thin films of bitumen samples were exposed to airstream of $163^{\circ} \mathrm{C}$ (RTFOT 8, ISL Product, France) according to ASTM D1754.

For UV aging, the bitumen samples were put in shells of $90 \pm 0.5 \mathrm{~mm}$ in diameter, which were exposed to UV radiation of a $500 \mathrm{~W}$ lamp for durations of 6 and 12 days at $50^{\circ} \mathrm{C}$ with average intensity of $10 \mathrm{~W} / \mathrm{m}^{2}$.

Bitumen samples were prepared in three conditions: samples unaged (S1-S4), samples aged in RTFO conditions (S5-S8), and samples aged in UV conditions (S9-S16). All samples are presented in Table 2. 


\begin{tabular}{|l|l|l|}
\hline Physical properties & Value & Standard \\
\hline Ductility $\left(@ 25^{\circ} \mathrm{C}, \mathrm{cm}\right)$ & 100 & ASTM D113 \\
\hline Softening point $\left({ }^{\circ} \mathrm{C}\right)$ & 48.6 & ASTM D36 \\
\hline Penetration $\left(@ 25^{\circ} \mathrm{C}, 0.1 \mathrm{~mm}\right)$ & 63 & ASTM D5 \\
\hline Density $\left(\mathrm{kg} / \mathrm{m}^{3}\right)$ & 1.03 & ASTM D70 \\
\hline
\end{tabular}

Table 3. Physical properties of bitumen sample.

Characterization methods. Fourier-transform infrared spectroscopy test (FTIR). Samples were tested through FTIR in transmission mode, between 400 to $4,000 \mathrm{~cm}^{-1}$ spectra range (Nexus, Thermo Nicolet Corp., USA). Chemical structure of materials can be determined with range of spectra in different chemical bands. The FTIR detects the reflection of the various infrared spectrum of chemical bonds. Carbonyl and Sulfoxide bonds result from UV radiation process, which forms carbon-carbon or carbon-hydrogen bonds. Carbonyl $(\mathrm{C}=\mathrm{O})$ and sulfoxide $(\mathrm{S}=\mathrm{O})$ functions were monitored with spectra of $1,700 \mathrm{~cm}^{-1}$, and of $1,030 \mathrm{~cm}^{-1}$ respectively. Both values can be determined from the range of oxidation in asphalt. $\mathrm{C}=\mathrm{O}$ group index $(\mathrm{IC}=\mathrm{O})$ and $\mathrm{S}=\mathrm{O}$ group index $(\mathrm{IS}=\mathrm{O}$ ) can be calculated by Eqs. (3) and (4):

$$
\begin{aligned}
\mathrm{I}_{\mathrm{C}=\mathrm{O}} & =\frac{\text { Area of carbonyl band centered around } 1700 \mathrm{~cm}^{-1}}{\sum \text { Area of spectral bands around } 1460 \text { and } 1375 \mathrm{~cm}^{-1}} \\
\mathrm{I}_{\mathrm{S}=\mathrm{O}} & =\frac{\text { Area of carbonyl band centered around } 1030 \mathrm{~cm}^{-1}}{\sum \text { Area of spectral bands around } 1460 \text { and } 1375 \mathrm{~cm}^{-1}} \\
\mathrm{CR} & =\frac{\text { Index of bitumen after }- \text { Index of bitumen before }}{\text { Index of bitumen before }}
\end{aligned}
$$

Rheological testing (DSR). A dynamic shear rheometer (DSR) (Malvern Kinexus Pro+, UK) was used to evaluate binder rheological properties in the domain of linear viscoelastic behavior, under different conditions (temperatures between 20 and $70{ }^{\circ} \mathrm{C}$, and frequency of $\left.10 \mathrm{rad} / \mathrm{s}\right)$. The complex shear modulus $\left(\mathrm{G}^{\star}\right)$, phase angle $(\delta)$, and rutting factor $\left(\mathrm{G}^{\star} / \sin \delta\right)$ of control bitumen and aged bitumen samples were investigated, based on the US-Standard AASHTO T 315.

Scanning electron microscope (SEM). A FE-SEM (TE-SCAN, MIRA III, Czech Republic) was used to consider and validate micro and nano structures of additives in bitumen samples. The morphology was characterized by focusing an electron beam on the sample surface. In order to prevent electron surface charging during imaging, the surface of sample was coated with a thin film of gold (10 nm film thickness) before FE-SEM imaging.

Mechanical tests. A Petrotest machine was used for identifying the bitumens' softening point ring and ball (PKA5, Germany) with standard ASTM D36. Ductility test (Infratest, 20-2356, Germany) was performed with a ductilometer machine $1,500 \mathrm{~mm}$ digital, according to Standard ASTM D113. An automatic penetrometer from Anton Paar (PNR 12, Germany) was used to determine Needle Penetration according to Standard ASTM D5. Table 3 summarizes the physical properties of bitumen determined in this study.

Received: 14 April 2020; Accepted: 12 June 2020

Published online: 08 July 2020

\section{References}

1. Yang, C. et al. Investigation of physicochemical and rheological properties of SARA components separated from bitumen. Constr. Build. Mater. 235, 117437 (2020).

2. Kaya, D., Topal, A. \& McNally, T. Relationship between processing parameters and aging with the rheological behaviour of SBS modified bitumen. Constr. Build. Mater. 221, 345-350 (2019).

3. Kaya, D., Topal, A., Gupta, J. \& McNally, T. Aging effects on the composition and thermal properties of styrene-butadiene-styrene (SBS) modified bitumen. Constr. Build. Mater. 235, 117450 (2020).

4. Wang, Y., Sun, L. \& Qin, Y. Aging mechanism of SBS modified asphalt based on chemical reaction kinetics. Constr. Build. Mater. 91, 47-56 (2015)

5. Petersen, J. C. A review of the fundamentals of asphalt oxidation: chemical, physicochemical, physical property, and durability relationships. Transp. Res. Circ. (E-C140) (2009).

6. Androjić, I. Ageing of hot mix asphalt. Građevinar 68, 477-483 (2016).

7. Xu, X. et al. Investigation of aging behavior and thermal stability of styrene-butadiene-styrene tri-block copolymer in blends. Polymer (Korea) 40, 947-953 (2016).

8. Karahancer, S. et al. Evaluating mechanical properties of bitumen and hot mix asphalt modified with nano ferric oxide. Constr. Build. Mater. 234, 117381 (2020).

9. Shafabakhsh, G. A., Sadeghnejad, M., Ahoor, B. \& Taheri, E. Laboratory experiment on the effect of nano $\mathrm{SiO}_{2}$ and $\mathrm{TiO}_{2}$ on short and long-term aging behavior of bitumen. Constr. Build. Mater. 237, 117640 (2020). 
10. Sedaghat, B., Taherrian, R., Hosseini, S. A. \& Mousavi, S. M. Rheological properties of bitumen containing nanoclay and organic warm-mix asphalt additives. Constr. Build. Mater. 243, 118092 (2020).

11. Pirmohammad, S., Majd-Shokorlou, Y. \& Amani, B. Experimental investigation of fracture properties of asphalt mixtures modified with Nano $\mathrm{Fe}_{2} \mathrm{O}_{3}$ and carbon nanotubes. Road Mater. Pavement Design https://doi.org/10.1080/14680629.2019.1608289 (2019).

12. Zahedi, M. \& Baharvand, B. Experimental study of Nano clay and crumb rubber influences on mechanical properties of HMA. J. Civ. Eng. Struct. 1, 10-24 (2017).

13. Wang, D. et al. Thermal oxidative and ultraviolet ageing behaviour of nano-montmorillonite modified bitumen. Road Mater. Pavement Design https://doi.org/10.1080/14680629.2019.1619619 (2019).

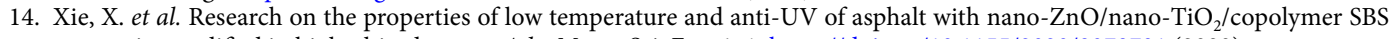
composite modified in high-altitude areas. Adv. Mater. Sci. Eng. 1, 1. https://doi.org/10.1155/2020/9078731 (2020).

15. Sun, X. et al. New preparation method of bitumen samples for UV aging behavior investigation. Constr. Build. Mater. 233, 117278 (2020).

16. Yang, S. et al. Ultraviolet and PAV aging procedures influence on rheological characteristics of Sasobit/SBS modified binder containing titanium dioxide nanoparticles. Pet. Sci. Technol. 36, 1524-1530 (2018).

17. Zhang, D., Zhang, H., Zhu, C. \& Shi, C. Synergetic effect of multi-dimensional nanomaterials for anti-aging properties of SBS modified bitumen. Constr. Build. Mater. 144, 423-431 (2017).

18. Cheraghian, G. Evaluation of clay and fumed silica nanoparticles on adsorption of surfactant polymer during enhanced oil recovery. J. Jpn. Petrol. Inst. 60, 85-94 (2017).

19. Lu, M. et al. Anti-aging behavior of amino-containing co-condensed nanosilica in polyethylene. Polym. Degrad. Stab. 154, 137-148 (2018).

20. Kleizienè, R., Paliukaite, M., \& Vaitkus, A. Effect of nano $\mathrm{SiO}_{2}, \mathrm{TiO}_{2}$ and $\mathrm{ZnO}$ modification to rheological properties of neat and polymer modified bitumen. In International Symposium on Asphalt Pavement and Environment 325-336 (2019).

21. Li, R., Xiao, F., Amirkhanian, S., You, Z. \& Huang, J. Developments of nano materials and technologies on asphalt materials-a review. Constr. Build. Mater. 143, 633-648 (2017).

22. Falcão, G. A., Almeida, T. G., Bardi, M. A., Carvalho, L. H. \& Canedo, E. L. PBAT/organoclay composite films-part 2: effect of UV aging on permeability, mechanical properties and biodegradation. Polym. Bull. 76, 291-301 (2019).

23. Zakani, B., Ansari, M. \& Grecov, D. Rotational rheometry of a fumed silica lubricating grease. J. Tribol. 142, 034501 (2020).

24. Üreyen, M. E., Kaynak, E. \& Yüksel, G. Flame-retardant effects of cyclic phosphonate with HALS and fumed silica in polypropylene. J. Appl. Polym. Sci. 137, 48308 (2020).

25. Ziari, H., Moniri, A. \& Norouzi, N. The effect of nanoclay as bitumen modifier on rutting performance of asphalt mixtures containing high content of rejuvenated reclaimed asphalt pavement. Pet. Sci. Technol. 37, 1946-1951 (2019).

26. Rezaei, S., Khordehbinan, M., Fakhrefatemi, S. M. R., Ghanbari, S. \& Ghanbari, M. The effect of nano- $\mathrm{SiO}_{2}$ and the styrene butadiene styrene polymer on the high-temperature performance of hot mix asphalt. Pet. Sci. Technol. 35, 553-560 (2017).

27. Liu, S., Zhou, S. B. \& Xu, Y. Evaluation of cracking properties of SBS-modified binders containing organic montmorillonite. Constr. Build. Mater. 175, 196-205 (2018).

28. Omar, H. A. et al. Determining the water damage resistance of nano-clay modified bitumens using the indirect tensile strength and surface free energy methods. Constr. Build. Mater. 167, 391-402 (2018).

29. Filippi, S., Cappello, M., Merce, M. \& Polacco, G. Effect of nanoadditives on bitumen aging resistance: a critical review. J. Nanomater. https://doi.org/10.1155/2018/2469307 (2018).

30. Cheraghian, G. et al. Effect of a novel clay/silica nanocomposite on water-based drilling fluids: improvements in rheological and filtration properties. Colloids Surf. A 555, 339-350 (2018).

31. Korobeinyk, A. V., Whitby, R. D., Mikhalovsky, S. V. \& Inglezakis, V. J. In situ production of high purity noble metal nanoparticles on fumed silica and catalytic activity towards 2-nitrophenol reduction. J. Phys. Chem. Solids 127, 28-34 (2019).

32. Omurlu, C., Pham, H. \& Nguyen, Q. P. Interaction of surface-modified silica nanoparticles with clay minerals. Appl. Nanosci. 6, $1167-1173(2016)$.

33. Tseng, T. F. \& Wu, J. Y. Preparation and structural characterization of novel nanohybrids by cationic 3D Silica nanoparticles sandwiched between 2D anionic montmorillonite clay through electrostatic attraction. J. Phys. Chem. C 113, 13036-13044 (2009).

34. Sasidharan, S., Shyni, P. C., Chaudhary, N. \& Ramakrishnan, V. Single crystal organic nanoflowers. Sci. Rep. 7, 17335 (2017).

35. Cheraghian, G. et al. Adsorption polymer on reservoir rock and role of the nanoparticles, clay and $\mathrm{SiO}_{2}$. Int. Nano Lett. 4, 114 (2014).

36. He, R., Zheng, S., Chen, H. \& Kuang, D. Investigation of the physical and rheological properties of Trinidad lake asphalt modified bitumen. Constr. Build. Mater. 203, 734-739 (2019).

37. AASHTO T. Standard method of test for determining the rheological properties of asphalt binder using a dynamic shear rheometer (DSR). American Association of State and Highway Transportation Officials (2012).

38. Petersen, R. E., Anderson, D. A., \& Button, J. W. Binder Characterization and Evaluation. Volume 3: Physical Characterization. SHRP-A-369 (National Research Council, Washington, DC, 1994).

39. Xu, S., Yu, J., Zhang, C. \& Sun, Y. Effect of ultraviolet aging on rheological properties of organic intercalated layered double hydroxides modified asphalt. Constr. Build. Mater. 75, 421-428 (2015).

40. Cao, Z. et al. Effect of etched layered double hydroxides on anti ultraviolet aging properties of bitumen. Constr. Build. Mater. 178, $42-50$ (2018).

41. Fang, C., Yu, X., Yu, R., Liu, P. \& Qiao, X. Preparation and properties of isocyanate and nano particles composite modified asphalt. Constr. Build. Mater. 119, 113-118 (2016).

42. Zhang, H. L., Su, M. M., Zhao, S. F., Zhang, Y. P. \& Zhang, Z. P. High and low temperature properties of nano-particles/polymer modified asphalt. Constr. Build. Mater. 114, 323-332 (2016).

43. Qing, Z., Qi-Cheng, L., Peng, L., Chuan-Sheng, C. \& Jiang-Rong, K. Study on modification mechanism of nano-ZnO/polymerised styrene butadiene composite-modified asphalt using density functional theory. Road Mater. Pavement Design 1, 1. https://doi. org $/ 10.1080 / 14680629.2018 .1552888$ (2018).

44. Schuler, B., Meyer, G., Peña, D., Mullins, O. C. \& Gross, L. Unraveling the molecular structures of asphaltenes by atomic force microscopy. J. Am. Chem. Soc. 137, 9870-9876 (2015).

45. Soleymanzadeh, A., Yousefi, M., Kord, S. \& Mohammadzadeh, O. A review on methods of determining onset of asphaltene precipitation. J. Pet. Explor. Prod. Technol. 9, 1375-1396 (2019).

46. Galooyak, S. S., Dabir, B., Nazarbeygi, A. E. \& Moeini, A. Rheological properties and storage stability of bitumen/SBS/montmorillonite composites. Constr. Build. Mater. 24, 300-307 (2010).

47. Zhu, J., Birgisson, B. \& Kringos, N. Polymer modification of bitumen: advances and challenges. Eur. Polymer J. 54, 18-38 (2014).

48. Golestani, B., Nejad, F. M. \& Galooyak, S. S. Performance evaluation of linear and nonlinear nanocomposite modified asphalts. Constr. Build. Mater. 35, 197-203 (2012).

49. Huang, X. J., Zeng, X. F., Wang, J. X., Zhang, L. L. \& Chen, J. F. Synthesis of monodispersed $\mathrm{ZnO@} \mathrm{SiO}_{2}$ nanoparticles for anti-UV aging application in highly transparent polymer-based nanocomposites. J. Mater. Sci. 54, 8581-8590 (2019).

50. Singh, L. P., Karade, S. R., Bhattacharyya, S. K., Yousuf, M. M. \& Ahalawat, S. Beneficial role of nanosilica in cement based materials-a review. Constr. Build. Mater. 47, 1069-1077 (2013). 
51. Yang, G. et al. The interaction of cellulose and montmorillonite in a hydrothermal process. J. Sol Gel. Sci. Technol. 82, 846-854 (2017).

52. Cheraghian, G. Synthesis and properties of polyacrylamide by nanoparticles, effect nanoclay on stability polyacrylamide solution. Micro Nano Lett. 12, 40-44 (2017).

\section{Acknowledgements}

The authors gratefully acknowledge financial support from the German Research Foundation (DFG) and the Fund of the Technische Universität Braunschweig. Part of Figs. 1, 8, and 13 were created with BioRender.com (under license number 307CB98D-0001 BioRender).

\section{Author contributions}

G.C. conceived and designed the experimental project. The paper was written by G.C. and M.P.W.

\section{Competing interests}

The authors declare no competing interests.

\section{Additional information}

Correspondence and requests for materials should be addressed to G.C.

Reprints and permissions information is available at www.nature.com/reprints.

Publisher's note Springer Nature remains neutral with regard to jurisdictional claims in published maps and institutional affiliations.

(c) (i) Open Access This article is licensed under a Creative Commons Attribution 4.0 International License, which permits use, sharing, adaptation, distribution and reproduction in any medium or format, as long as you give appropriate credit to the original author(s) and the source, provide a link to the Creative Commons license, and indicate if changes were made. The images or other third party material in this article are included in the article's Creative Commons license, unless indicated otherwise in a credit line to the material. If material is not included in the article's Creative Commons license and your intended use is not permitted by statutory regulation or exceeds the permitted use, you will need to obtain permission directly from the copyright holder. To view a copy of this license, visit http://creativecommons.org/licenses/by/4.0/.

(C) The Author(s) 2020 